\title{
Febrile encephalopathy and diarrhoea in infancy: do not forget this culprit
}

\author{
Arushi Yadav, ${ }^{1}$ Jogender $\mathrm{Kumar}^{\oplus 2}$
}

${ }^{1}$ Radiodiagnosis and Imaging, SMS Medical College and Hospital, Jaipur, Rajasthan, India ${ }^{2}$ Pediatrics, Post Graduate Institute of Medical Education and Research, Chandigarh, India

\section{Correspondence to Dr Jogender Kumar, jogendrayadv@gmail.com}

Accepted 17 June 2019

\section{DESCRIPTION}

An 8-month-old partially immunised infant girl presented with a history of fever, loose stool and decreased responsiveness for the past 2 days. On examination, she was moderately dehydrated and had poor sensorium. However, the rest of the systemic examination was normal. The complete blood count, liver and kidney function tests, as well as electrolytes, were also normal. For this illness, intravenous antibiotics were given and dehydration management was done as per protocol. In view of febrile encephalopathy with acute gastroenteritis possibility of enterovirus, rotavirus and bacterial (Salmonella, Shigella, Campylobacter, Escherichia coli) encephalitis were considered and lumbar puncture was done. The cerebrospinal fluid analysis was normal (Acellular, protein: $54 \mathrm{mg} / \mathrm{dL}$, glucose: $63 \mathrm{mg}$ / $\mathrm{dL}$, Gram stain-negative and culture-sterile). Stool routine and microscopic analysis did not show any ova/cyst or pathogenic organism. The facility of rotavirus and enterovirus panel was not available in the hospital hence; MRI of the brain was done to ascertain the aetiology of encephalopathy. T1 and T2-weighted MRI sequences did not show any changes in the signal intensity of the white matter (figure 1) but the diffusion-weighted imaging showed extensive and symmetric areas of diffusion restriction in the subcortical (including $U$ fibres) as well as deep white matter of bilateral frontal and parieto-occipital lobes at the level of the lateral ventricles (figure 2). These neuroimaging findings are consistent with rotavirus encephalopathy. Meanwhile, we managed the testing for rotavirus

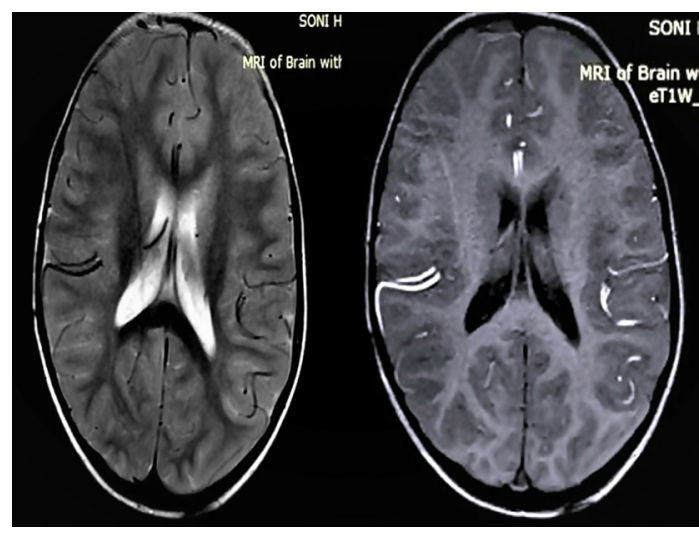

Figure 1 Axial T2-weighted turbo spin echo sequence (left) and T1-weighed fast field echo sequence (right) of the brain at the level of ventricles did not show any appreciable signal changes.

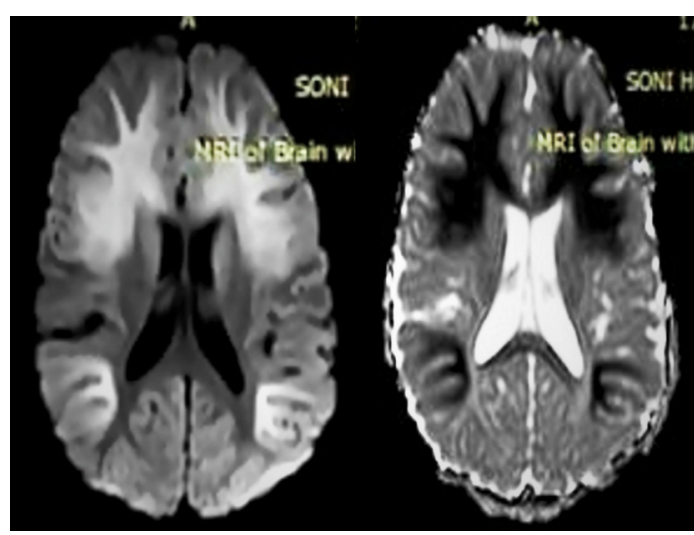

Figure 2 Axial diffusion-weighted imaging sequence (left) at the level of lateral ventricles shows confluent diffuse hyperintense signal involving subcortical (including $U$ fibres) and deep white matter of bilateral fronto-parieto-occipital lobes. Apparent diffusion coefficient map (right) shows diffuse hypointensity in corresponding areas.

antigen in the stool (enzyme immunoassay) from a laboratory and it turned out to be positive. Her sensorium also improved rapidly over the next 3 days and she was discharged on the sixth day. The neurological examination was normal at discharge and until 1 year of age. However, after that she lost to follow-up; therefore, a further neurological assessment could not be done.

Along with gastroenteritis, rotavirus may also involve the central nervous system (CNS), liver, heart, kidney and respiratory tract. ${ }^{1}$ Around 5\% of rotavirus gastroenteritis have CNS involvement which may be in the form of meningitis, encephalitis, encephalopathy, seizures and Guillain-Barre syndrome. ${ }^{2} 3$ During infancy, the concomitant presence of febrile encephalopathy and gastroenteritis should raise the suspicion of

Learning points

- In infants presenting with febrile encephalopathy and acute gastroenteritis, the rotavirus infection should be considered in differential diagnoses.

- The neuroimaging findings of rotavirus encephalopathy are very classical and can differentiate from other aetiologies.

- Rotavirus infection is a vaccine-preventable disease and routine vaccination should be encouraged to prevent it. 
rotavirus infection. The classical neuroimaging findings are 'subtle or no change in T1 and T2 weighted sequences, but marked symmetric diffusion restriction in periventricular white matter, corpus callosum or thalamus'. ${ }^{4}$ This pattern of white matter injury can be seen in parecho and enterovirus encephalopathy as well but, overtly restricting signals on diffusion sequences with no/subtle changes on conventional T1 and T2 weighted spin echo sequences is quite specific for rotavirus encephalopathy and gives an edge over the other two differentials. ${ }^{4}$ Recently 'rotavirus cerebellitis' is also described. ${ }^{5}$ Therefore, in the absence of the facility for rotavirus antigen testing, neuroimaging may serve as a surrogate of definitive diagnostic tests. A neurological sequel can be seen in $30 \%-40 \%$ of cases, therefore, long term neurological follow-up is recommended.

Rotavirus is a vaccine-preventable disease and does not have any specific antiviral treatment. In developing countries (like India) the coverage of the vaccine is very poor and the disease, have a major impact on childhood mortality. This case highlights the unmet need of routine rotavirus vaccine coverage.
Acknowledgements The authors would like to acknowledge the pediatric team of SMS Medical College for managing the patient and providing us support during writing of the manuscript.

Contributors AY did neuroimaging and reached upto the diagnosis. AY conceptualised the idea of writing and drafted the manuscript. JK did proofreading, provided critical inputs in writing the manuscript. Both the authors approved the final version of the manuscript.

Funding The authors have not declared a specific grant for this research from any funding agency in the public, commercial or not-for-profit sectors.

Competing interests None declared.

Patient consent for publication Obtained.

Provenance and peer review Not commissioned; externally peer reviewed.

\section{REFERENCES}

1 Rath BA, Gentsch J, Seckinger J, et al. Rotavirus encephalitis with basal ganglia involvement in an 8-month-old infant. Clin Pediatr 2013;52:260-4.

2 Wong V. Acute gastroenteritis-related encephalopathy. J Child Neurol 2001;16:906-10

3 Incecik F, Hergüner MO, Altunbașak S, et al. Acute encephalopathy associated rotavirus gastroenteritis. J Pediatr Neurosci 2009:4:141-3.

4 Yeom JS, Park CH. White matter injury following rotavirus infection in neonates: new aspects to a forgotten entity, 'fifth day fits'? Korean J Pediatr 2016;59:285-91.

5 Takanashi J, Miyamoto T, Ando N, et al. Clinical and radiological features of rotavirus cerebellitis. AJNR Am J Neuroradiol 2010;31:1591-5.

Copyright 2019 BMJ Publishing Group. All rights reserved. For permission to reuse any of this content visit

https://www.bmj.com/company/products-services/rights-and-licensing/permissions/

BMJ Case Report Fellows may re-use this article for personal use and teaching without any further permission.

Become a Fellow of BMJ Case Reports today and you can:

- Submit as many cases as you like

- Enjoy fast sympathetic peer review and rapid publication of accepted articles

- Access all the published articles

- Re-use any of the published material for personal use and teaching without further permission

\section{Customer Service}

If you have any further queries about your subscription, please contact our customer services team on +44 (0) 2071111105 or via email at support@bmj.com.

Visit casereports.bmj.com for more articles like this and to become a Fellow 